Available online on 15.11.2016 at http://jddtonline.info
(C) 2016, publisher and licensee JDDT, This is an Open Access article which permits unrestricted
noncommercial use, provided the original work is properly cited

Review Article

\title{
ADVANCES IN SOLID DISPERSION TECHNOLOGY AND ITS APPLICATIONS IN THE DEVELOPMENT OF SOLID DOSAGE FORMS
}

\author{
Bhirud, Yogesh D.* and Phalak Harshada M. \\ Department of Pharmaceutics, Loksevak Madhukarrao Chaudhari College of Pharmacy, Faizpur, Maharashtra 425503, India
}

\begin{abstract}
Amorphous solid dispersions are extensively used as a strategy for improving the bioavailability of poorly water - soluble compounds in past decade. Therefore, the application of this technique proves to be an important stratagem for pharmaceutical companies. However, the in - depth knowledge of the solid dispersion is desired for the scale up of formulation, from laboratory scale to industrial scale. Hydrophilic polymers are used for preparation of solid dispersion such as polyvinylpyrrolidone, hydroxylpropylmethylcellulose, polyethylene glycols. Recently some new carriers like cyclodextrins, gelucire, vitamin E TPGS and many more has been explored as a carrier for the solid dispersion technology. Using of these polymers has its own advantages and disadvantages. Method of preparation also influences dissolution profile of solid dispersion. In this review, we intend to discuss the recent advances in the field of solid dispersions and their use in multicomponent systems. This review also elaborates the method of preparation and its correlation with the in-vivo absorption properties.
\end{abstract}

Keywords: Solid dispersion, Multicomponent systems, Hydrophilic carriers, Bioavailability

*Corresponding author

Bhirud Yogesh D., Department of Pharmaceutics, Loksevak Madhukarrao Chaudhari College of Pharmacy, Faizpur, Maharashtra 425503, India. Email: yogeshd.bhirud@gmail.com

Article Info

Received 26 July 2016; Review Completed 04 Nov 2016; Accepted 04 Nov 2016, Available online 15 Nov 2016

URI: http://iddtonline.info/index.php/iddt/article/view/1316

Cite this article as: Bhirud Yogesh D, Phalak Harshada M, Advances in solid dispersion technology and its applications in the development of solid dosage forms, Journal of Drug Delivery \& Therapeutics. 2016; 6(6):40-47 DOI: http://dx.doi.org/10.22270/jddt.v6i6.1316

\section{INTRODUCTION}

In recent years, many delivery systems drugs emerged in order to model the kinetics release, improve the absorption and increase stability drugs. From this arose the main difficulties with regard to the development and the therapeutic activity of many drugs, which results in large part to the low aqueous solubility of drugs. Of new chemical entities from 35 to $45 \%$ have this characteristic, leading to a low rate active absorption or the incomplete release ${ }^{1,2}$. The aqueous solubility of a drug is prerequisite to absorption and obtaining a clinical response for most drugs administered by orally ${ }^{3}$. Poorly soluble drugs are slowly absorbed when compared to those who have high solubility in water $^{4}$. Thus, some techniques can be used to increase the solubility of drugs, independent of their chemical structure and dimension Molecular space ${ }^{5,6}$. Since solid dispersion increases the solubility of the drugs, it has become one of the most active areas of research in the pharmaceutical field. this technique It produces a significant reduction in particle size drug with increased uniformity and surface contact, allowing dissolution and faster absorption ${ }^{7}$. The problems that limited the pioneering studies for commercial application of SD involved method preparation, properties reproducibility of the physical- chemical, the dosage formulation, manufacturing process on a large scale and chemical stability of the drug and vehicle. However, the use of this system in some formulations, such as in the development technologies for direct filling into SD hard gelatin capsules, renewed interest that system for preclinical use, clinical development and commercial, large-scale pharmaceutical ${ }^{8}$. However, despite the 
progress made, there few reports of the application of this technique in commercial use ${ }^{9}$, demonstrating the need for the depth knowledge about the possibilities applications, in order to obtain drugs that ensure the desired therapeutic effect, using a simple technique and low cost for industries pharmaceutical ${ }^{10}$.

\section{ADVANCES AND APPLICATIONS OF SOLID DISPERSIONS}

Solid dispersions are obtained by separate technological processes that are to disperse pharmacologically active component in a carrier or matrix in the solid state, in order to improve the solubility and increase the rate of dissolution, which, in turn, modulates the therapeutic action due to increased bioavailability ${ }^{11,12}$. They have also been used to increase the chemical stability of drugs in solution or suspension ${ }^{13}$.

The first generation of SD was prepared employing crystalline carriers. These carriers include sugars and urea, which have in SD disadvantages crystal formation, which, being thermodynamically more stable, they do not release the drug with the desired speed ${ }^{14}$.

At the end of previous decade, it was observed that to obtain SD could be more effective when the state obtained amorphous. Was initiated, then the second generation of SD characterized by the preparation of systems in which the drug It is molecularly dispersed unevenly on an amorphous carrier ${ }^{15}$. These carriers were reported in 1971 by Chiou, demonstrating that hydrophilic polymers. They could be used to improve the solubility and degree of dissolution of poorly soluble drugs. Examples of such polymers, we can mention synthetic, which include polyvinylpyrrolidone (PVP), and polyethylene glycol (PEG), and natural cellulosic derivatives, as hydroxypropylmethylcellulose (HPMC), ethylcellulose and hydroxypropylcellulose $\mathrm{e}^{16}$.

Although the drug in the amorphous state has a faster dissolution when compared to their structure crystalline, the former is not physically stable, and possible recrystallization of the obtained product during life period of its use, easily verified through the technique of X-ray diffraction ${ }^{17}$. In order to work around this problem, studies performed demonstrated that the dissolution profile SD could be improved by adding surfactants or agents with the emulsifying property. It began, thus the third generation of SD. This was developed in order to achieve the highest degree of bioavailability of poorly soluble drugs and SD stabilize by preventing recrystallization of the drug ${ }^{14,18}$.

These systems are capable of reducing the size drug particle almost molecular level, providing a better wettability and dispersibility the carrier, the formation of an amorphization of the drug and carrier ${ }^{19}$. SD Accordingly, dissolution of the carrier or mixtures one determines the drug release profile $\mathrm{e}^{20}$. As an example of the use of this system we can mention the study by Liu and $\mathrm{Wang}^{21}$, that used as the third surfactant Polysorbate 80 component in the preparation of SD containing oleic acid and PVP K-30, which played an important increment in dissolution rate, when compared to the biphasic system containing only the polymer and the drug. The advantages related to the SD when compared conventional capsule and tablet formulations conventional (Figure 1) is that the formulation is disintegrated in the form of particle size less than $1 \mathrm{uM}$ and is, therefore, more easily dissolved, whereas, in conventional formulations, the size particle is greater than 5 micrometres ${ }^{7,8}$.

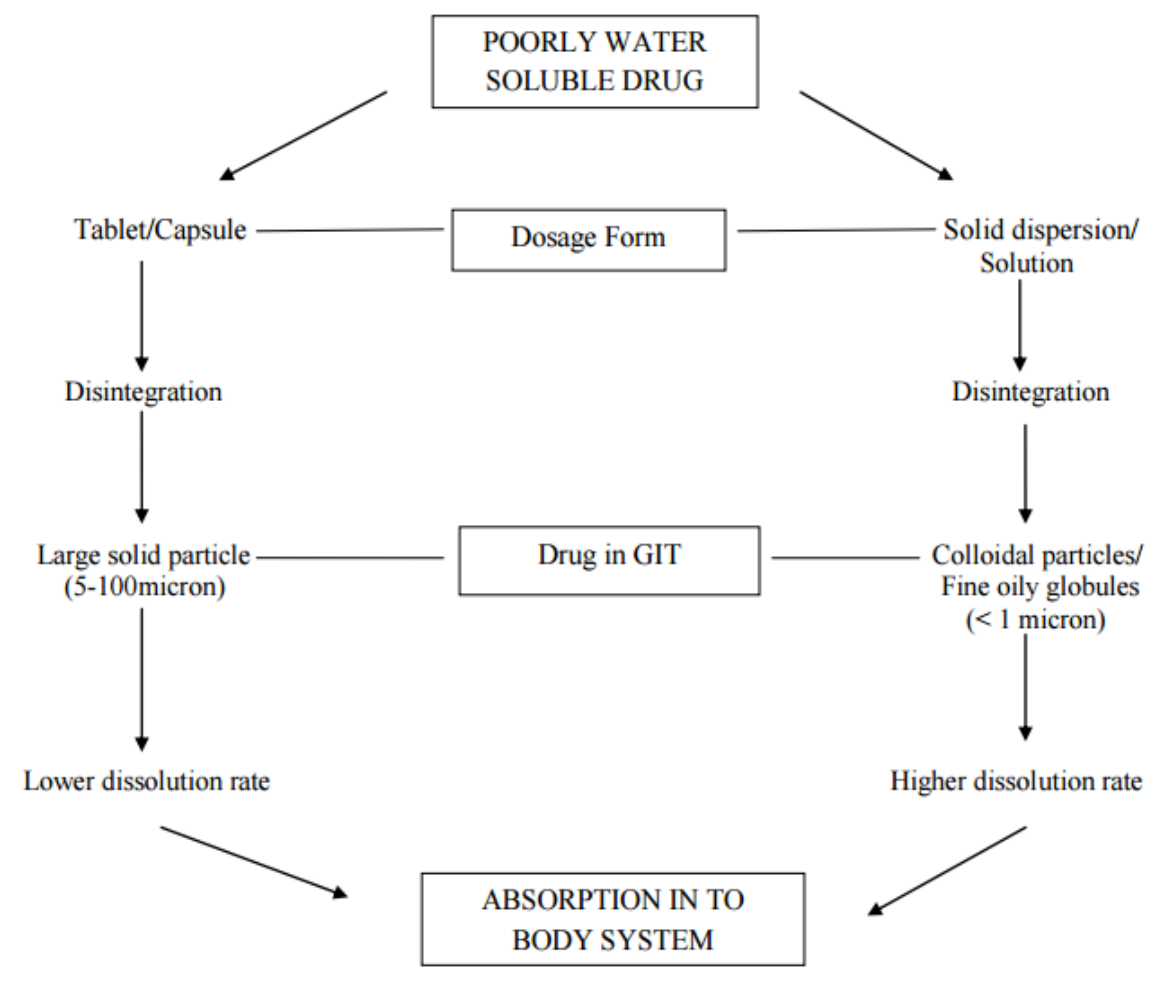

Figure 1: Schematic representation of the increased bioavailability of poorly water soluble drugs by $\mathrm{SD}^{8}$ 
In addition, changes in the state of the drug, solid crystalline to the amorphous state is a major reason that lead to increased solubility, apparently by improving the contact between the drug and the dissolution, reducing aggregate formation, and clusters and favoring the stability of the dispersions ${ }^{11,22}$.

The higher aqueous solubility in the amorphous state based on the solvation energy involved in the process dissolution due to the arrangement of the molecules that system, which is arranged at random. Therefore, in this case, low energy solvation is required to separate them and homogenize them in half, providing a faster and effective dissolution. Thus, the development formulations containing the drug in amorphous form are often beneficial in terms of dissolution and bioavailability $^{23}$.

The dissolution of the drug contained in the SD is influenced by many other factors, including the method used in obtaining, proportion and characteristics of the carrier, the $\mathrm{pH}$ of the dissolution medium temperature and particle surface characteristics resulting from $\mathrm{SD}^{24}$. Among the mentioned influences, the more relevant in determining the properties of the SD are the methods of preparation and types of carriers used.

\section{METHODS OF PREPARATION OF SOLID DISPERSIONS}

Several studies have shown that the properties Physicochemical SD obtained by different preparation methods are directly related. Thus, this fact is established as a prerequisite SD development, evaluation is required the interference of the method used, aiming to choose that it is more efficient with regard to dissolution and stability of the products obtained in storage conditions ${ }^{7}$.

The methods of obtaining the dispersions commonly used are the melting method, solvent melting-solvent and kneaded ${ }^{4}$. However, they are already being mentioned other methods, including supercritical fluid and spray drying, which is already commonly used as Methods of obtaining inclusion complexes using cyclodextrins, being successfully used to Preparation of $\mathrm{SD}^{25}$.

\section{Melting Method}

Because of the toxicity and environmental problems associated with the use of organic solvents, the use the fusion method represents an advantageous means in Preparation of SD when the drug is stable Thermal. However, its use is inappropriate when there polymorphism due to transition that may occur during fusion between the polymorphic forms ${ }^{26,27}$.

In this method, the drug and carrier are heated the temperature slightly above its melting point, and the drug is incorporated into the molten carrier. The system remains under heating to obtain a solution homogeneous, macro and microscopically. Posteriorly, the system is cooled under constant stirring. In this case, there is a greater possibility of breaking the crystalline state of the drug to the amorphous state due to the use of high temperatures. However, the possibility of Miscibility halfway between drug and carrier due to the high viscosity of the polymer in the molten state, in addition, degradation of labile drugs ${ }^{28}$.

When the drug has a high solubility the carrier, it can remain "dissolved" in the state solid, originated what is known as a solid solution. Under these conditions, the reduction in particle size provides a peak molecular dispersion of the drug the carrier ${ }^{29}$.

\section{Solvent Method}

In this method, also known as method coevaporation, the drug and carrier are solubilized Common organic solvent which is then evaporated with constant stirring, yielding a dry residue and solid. Solvent removal can be performed in vacuum rotaevaporator or in a lyophilizer. This method many It is sometimes confused with the co - precipitation; However, In this case, the drug and polymer are dissolved, and subsequently, precipitation is induced by adding a cosolvent. The nature of the solvent and its rate and temperature evaporation are particularly critical in this method. At the same time, the main disadvantage of this method is the use of organic solvents and the formation of residues, despite being a simple, inexpensive and used in laboratory scale, in addition to the difficulty of selecting a common solvent to dissolve the drug with hydrophobic characteristics and hydrophilic carrier ${ }^{13}$.

\section{Method fusion-solvent}

In this method, the polymer is heated to slightly above its melting point and the drug, previously solubilized in organic solvent, it is incorporated into the molten carrier. Subsequently, the system is cooled under constant agitation for dry lyophilization, if necessary. This method becomes useful for drugs that have a high melting point or thermolabile ${ }^{30}$.

\section{Kneading Method}

In this method, the polymer and drug are mixed by geometric dilution. The mixture is malaxada with adding the amount of solvent minina (equivalent to $30 \%$ of the post of weight) in order to obtain a moist consistency. Industrially, a mixture of components is performed in a malaxadora, and in this case, required some adjustments in the methodology used, initially at the level bench, which can cause some modifications of the physical and chemical characteristics and pharmacotechnical the product. The drying of the material can be done in an oven or directly in malaxadora followed by pulverization to standardize the size particle. Due to the simplicity, the high throughput and the scale transposition facility, this method is the most widely used in the pharmaceutical industry ${ }^{31}$.

\section{Atomization method for spray dried}

This technique has the same principles as the method solvent which, as well as other techniques that have been developed differs only in the way of drying solvent, to produce different characteristics of products obtained. In this case, the process produces SD particles with reduced size and amorphous, with a high rate 
dissolution and minimal residual solvent in the systems, and the possibility of industrial implementation ${ }^{25}$. Although the spray drying technique is one technology that requires high investments in facilities and operations, there are many reasons why the same is widely used, despite the cost. It is It has recently been used mainly in increasing the class of drugs bioavailability Biopharmaceutical II (low solubility and high permeability), resulting in products with better Functional properties, such as particle size, compaction and dissolution rate ${ }^{25,32}$. For drugs of this class, solubility is the limiting factor of absorption and data and In vitro studies may be useful ${ }^{33}$. The advantages related to this technique include producing particles of consistent quality, easy compared to continued use, applicability of the technique both in sensitive material and heat resistant and ability to process various types of raw materials, production of sustained release systems, and increase water solubility of drugs ${ }^{34}$.

\section{Method supercritical fluid}

The process of supercritical fluid has emerged as an alternative method to the solvent method, forming small particle size precipitation and low organic matter content, with also better flow. Powder flowability is important when commercialization of the process is desired $^{35}$. Carbon dioxide is currently $\mathrm{We}$ used this technique due to the advantages associated with its use, as a non - toxic gas, non - flammable, inexpensive and low critical temperature, making it attractive in the processing of heat sensitive drugs and the process solvent removal extremely controlled ${ }^{13}$. Although the results promising described in the literature, is a technique still Experimental and having an initial cost very high ${ }^{36}$.

\section{CARRIERS USED IN SOLID DISPERSIONS}

In the preparation of SD, many substances can be used, among them polyols (mannitol and sorbitol), organic acids (citric acid), urea, poloxamer, chitosan and polyglycolide glycerides. However, hydrophilic polymers are the most cited and utilized as carriers solids for dispersions ${ }^{37}$. The polymer properties are directly related to the chemical nature of monomers, the molecular weight and macromolecular structure ${ }^{38}$. Polymers or combinations of polymers and surfactants have been proposed in an attempt to adapt the physicochemical properties of the polymers to the system solid dispersion ${ }^{11}$. Besides that, the choice of polymeric carriers may determine the inhibition or the period that the dispersed drug may come to recrystallize, this factor being dependent on the degree of drug miscibility in polymer determined humidity ${ }^{39}$.

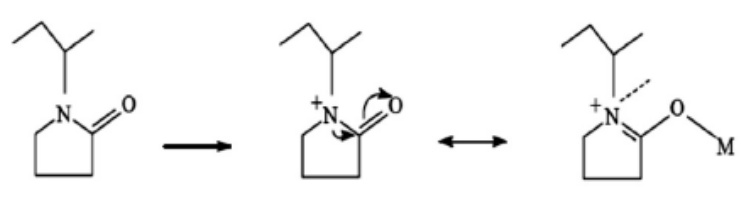

Figure 2: Representative monomeric structures of PVP and bond formation between $\operatorname{drug}(\mathrm{M})$ and the polymer.
Among the most reported hydrophilic polymers literature for the preparation of the SD have the PEG, PVP, and HPMC, which are often employed in various Pharmaceutical formulations due to low toxicity, rate of rapid solidification, high aqueous solubility, available in various molecular weights, cost economic and physiologically tolerable ${ }^{4,21}$.

\section{Polyvinylpyrrolidone (PVP)}

The PVP also known as Povidone, is a homopolymer of $\mathrm{N}$-vinyl-2-pyrrolidone capable of forming hydrogen bonds with other molecules to contain electrons donor groups such as nitrogen and oxygen ${ }^{40}$. It is presented as an amorphous white powder flow free and its molecular weight is often reported by K Fikentscher value derived from the viscosity of this solution. The variation of molecular weight between 10,000 700,000 shows a wide range of applications pharmaceutical industry due to high water solubility. For SD, PVP K-12 and K-30 (MW 2500-50000) are the most widely used. Above 50,000, aqueous solubility PVP decreases, and its viscosity directly increased and may be used for controlled release $\operatorname{drugs}^{4,41}$.

The PVP provides a lactam ring as part of the monomeric unit. The high polarity of the ring may be attributed to strong stabilization resonance shown in Figure 2, facilitated by the planar geometry of the ring, contributing in connection with poorly water - soluble drugs (M) via hydrogen bonding, enabling the process of forming $\mathrm{SD}^{2,} 42,43$. In general, the glass transition temperature of PVP is high, and for PVP K-30 is $163^{\circ}$ C. Therefore, PVP has limited application to the preparation of the SD fusion method. Due to their good solubility in a wide variety of organic solvents is particularly suitable for the preparation by the solvent method $^{37}$.

Increased drug dissolution bit provided by watersoluble polymers, in general, It is through maximizing the porous structure of a water soluble polymer matrix, such as PVP. Therefore, the aim of this feature is to increase the surface drug contact dissolutor means, facilitating solubilization process ${ }^{44}$.

\section{Polyethylene glycol (PEG)}

The use of PEG, the polymer of ethylene oxide, characterized by the units $(-\mathrm{CH} 2 \mathrm{CH} 2 \mathrm{O}-)$ repeating, becomes advantageous in obtaining $\mathrm{SD}$ due to its physicochemical properties. Among them, the presence of: hydroxyl groups $(\mathrm{OH})$ as electron donors; responsible for the interaction with hydrophobic compounds through hydrogen bonds; biocompatibility; odorless characteristics; neutral and non - irritating; low toxicity in vivo and solubility in various solvents organic and water, providing a quick release the dispersed drug and facilitating the process of obtaining the solvent method ${ }^{45,46}$.

PEG application of the limits can be extended by biodegradation in response to factors specific, such as increased temperature or $\mathrm{pH}$ (Leuner \& Dressman, 2000; Koo et al . , 2009). PEG has many PM (200300000) and different melting temperatures, which 
provides a wide industrial application in processes involving heating ${ }^{4}$. Commonly, the SD and preparation of solutions are used PEGs with MW between 1500 and 20,000. The molecular weight increase PEG leads to elevation of its viscosity and its point fusion (PF). In the molecular structures (MW) of up to 600, the PEGs are fluid; in the range of 800-1500, They show greater consistency; between 2000 and 6000, in general, waxy present and those aspects above with PM 20,000, have the form of crystals brittle temperature environment ${ }^{47}$.

The variation of PEGs $\mathrm{PF}$ is less than $65^{\circ} \mathrm{C}$; per example, PEG 1000 is $30-40{ }^{\circ} \mathrm{C}$, PEG $400050-58^{\circ} \mathrm{C}$ and PEG 20000 is $60-63{ }^{\circ} \mathrm{C}^{48}$. These mp low temperatures are advantageous for obtaining SD by the melt method ${ }^{47,49}$.

\section{Hydroxypropylmethylcellulose (HPMC)}

Among the polymeric materials, derived from pulp are quite popular, especially HPMC. This polymer is described in the European Pharmacopoeia and a portion of the ortho-methylated cellulose and cellulose ortho-2hydroxypropylated. Sorts up with a cellulose ether wherein the hydrogens and the hydroxyl groups of cellulose they were partly replaced by alkyl groups to alter the characteristics of native cellulose. The popularity of HPMC is linked to the nature non - toxic, biocompatibility and biodegradability and small influence of processing variables on drug release, and its compression facility. One of the most important features of this polymer linear hydrophilic is its solubilization capacity Low - solubility drugs compared to other Water - soluble polymers. In addition, its use prevents or slows the effect of nucleation which leads to recrystallization of the drug may be associated with other polymers different formulations, and according to the viscosity of the HPMC type chosen, additionally enables one extended - release ${ }^{50}$.

HPMC is very soluble in water, mixtures hydroalcoholic and chlorinated solvents, not being soluble in pure ethanol $^{51}$. Usualmente is reported preparing SD using mixtures of HPMC dichloromethane solvents by the solvent method ${ }^{52}$. The physicochemical properties of this polymer are strongly affected by changes in the group's methoxy $(\mathrm{OCH})$ and hydroxypropoxy $(\mathrm{OCH} \mathrm{CH}$ $(\mathrm{CH}) \mathrm{OH}$ ) and the molecular weight. The United States Pharmacopeia (USP) distinguishes four different types of HPMC: HPMC 1828 HPMC 2208 HPMC 2906 and HPMC 2910. The first two Numbers indicate the percentage of methoxy groups and the last two groups the percentage of hydroxypropoxy, determined after drying at $1058^{\circ} \mathrm{C}$ for $2 \mathrm{~h}^{53}$. In obtaining $\mathrm{SD}$, it is reported to use of different types of HPMC, there is not a predominance of a particular type, demonstrating that the choice is made according to the intended purpose.

\section{New carriers}

The use of amphiphilic carriers consisting Gelucire ${ }^{\circledR}$ as lipid and Vitamin E TPGS (TPGS) has attracted recent interest in development studies solubility drugs. The lipid substances low hydrophilic lipophilic balance (HLB) may be employed to reduce the dissolution rate of drugs and high HLB are used for rapid release ${ }^{19}$.
Gelucires () are saturated glycerides polyglycosylated consisting of mono-, di- and tri-glycerides and monoand di-esters of polyethylene glycol fatty acid. While on contact with aqueous fluids, this substance forms a fine emulsion enabling the solubilization of the substance active. Moreover, their properties allow control of drug release formulation ${ }^{19}$.

The TPGS is a soluble derivative of vitamin $\mathrm{E}$ in water consisting of polar hydrophilic group polyethylene glycol and a lipophilic tail, consisting tocopherol succinate, resulting in a surfactant of amphiphilic properties (EHL 13). As well as the Gelucires ${ }^{\circledR}$, the TPGS has the advantage of forming emulsions spontaneously, thus facilitating the solubilization of lipophilic drugs when present in an aqueous medium by a low critical micelle concentration, ensuring increased gastrointestinal absorption ${ }^{54}$. The use of Gelucires Pool and TPGS PVP formulations also shown to be effective in reducing the rate of crystallization, when common event using carriers with low melting point., and, however, increased bioavailability major advantage offered by these associations ${ }^{54}$. The Labrasol $\AA$, a surfactant of the same nature Gelucires $₫$ chemistry, has also been extensively exploited to increase the solubility and permeability gut and oral bioavailability of some drugs soluble in water, presenting itself as a liquid Transparent and HLB value of $14^{19,55}$.

Along with these, the poloxamers known commercially as Lutrol $\AA$, have also been reported in the preparation of SD. His interim constitution units hydrophilic and hydrophobic copolymer enables your wide use as solubilizing agents, wetting agents and suspension stabilizers. As an example of this class, It has Poloxamer 188 , which is a copolymer composed of two hydrophilic polyoxyethylene chains linked by hydrophobic polyoxypropylene chain, which has been often selected as a carrier in the dissolution of poorly water-soluble drugs 56 .

\section{Solid dispersions multicomponent systems cyclodextrins}

Cyclodextrins (CSD) are a new class of pharmaceutical excipients used successfully industry, particularly known to form an inclusion complex with a variety of molecules low water solubility, both in solution and in the state solid (Ribeiro et al., 2003). Due to its frustoconical structure, comprising D-glucose molecules, has a capacity of complexation Molecular by replacing molecules Water found in the middle and into the cavity, which They have high enthalpy per guest molecules hydrophobic characteristics. It is process energy viable for promoting change favorable enthalpy, entropy increase, and reduction total energy of the system, factors that contribute to the increased stability of the complex formed. interactions electrostatic Van der Waals, hydrophobic interactions, and hydrogen bonds also contribute to forming and stabilizing inclusion complexes ${ }^{57}$. However, the complexation efficiency CDs can often have low, leading consequently the use of significant amounts CDs to solubilize small proportions of molecules Hydrophobic. Thus, despite the advances in the field resulting 
pharmacist CD for use in improving solubility, they are not always sufficient and it is necessary the ongoing effort in trying to improve formulations containing complex drug-CD ${ }^{58}$.

To this end, it comes to proposing getting ternary complex between drug and a third CD component. Among the substances that have been used additionally in the formation of this system, we can mention the hydroxy acids and water soluble polymers ${ }^{59}$, followed generally by heat treatment promotes the formation of polymeric complexes also called complexes or systems / complexes multicomponent. This association has been of interest relevant to scientific and technological knowledge due to physical, chemical and biological of drugs that are optimized along with this Association ${ }^{60}$. This technique causes a synergistic effect in solubility, stability, and ability to complexation the active ingredient, which lower quantities $\mathrm{CD}$ present in the formulation, including solutions Aqueous ${ }^{38}$. For polymers which are more used, it was shown that the solubilizing effect the $\mathrm{CD}$ is further enhanced by the use of same at low concentrations ${ }^{61}$.

The major classes of water-soluble polymers employed in producing multicomponent systems complexation are: (1) Polymers semisynthetic derivatives cellulose: methylcellulose (MC), hydroxyethylcellulose (HEC), hydroxypropylcellulose (HPC), HPMC, hydroxyethyl methylcellulose (HEMC) and sodium carboxymethylcellulose (Na-CMC); (2) natural polysaccharides or polypeptides: inulin, pectin, sodium alginate, agar, casein, carrageenan, chitosan, scleroglucan and mucin; (3) synthetic polymers polyvinyl type or copolymers of acrylic acid and other polymers (neutral polymers or ionic charge): PVP, polyvinyl alcohol (PVA) and hexadimethrine bromide $(\mathrm{HDMB})^{58}$. The interactions between polymers and CD have been intensely studied. In one such study, was verified that among various polymers, the $\alpha-C D$ complex is a more efficiently with PEG. Other polymers such as the polypropylene and polyisobutylene form best complexes with $\beta-C D$ and $\gamma-\mathrm{CD}^{62}$.

However, it was also reported that in solutions Aqueous, the polymers may increase as much decrease complexation with CDs. As an example addition, we propylene glycol, which reduces complexation of some drugs, acting as a competitor guest molecule while adding PVP increased significantly the stability constants of some complex drug-CD, probably for training ternary complex or cocomplexes ${ }^{62}$. As seen in the complex formed between hydrocortisone and hydroxypropyl- $\beta$-ciclodextina (HP- $\beta-\mathrm{CD})$, which showed an increase in the constant association of the complex 890 to $1070 \mathrm{M}-1$, in the presence $0.25 \%$ (w / v) $\mathrm{PVP}^{63}$.

The evaluation of the increase of aqueous solubility obtained from such interaction is performed by Physical and chemical characterization by different techniques analytical. Ribeiro et $\mathrm{al}^{60}$. confirmed the formation of multi-component complexes of Vinpocetine with tartaric acid, water soluble polymers such as hydroxypropylmethylcellulose (HPMC), and PVP K-30 and sulfabutiléter- $\beta$-cyclodextrin $(\mathrm{SBE} \beta \mathrm{CD})$ in the solid state, by electron microscopy (SEM) thermal analysis, X-ray diffraction, spectroscopy infrared Fourier transform and resonance Nuclear magnetic. These characterizations demonstrate as the characterization of the complexes formed are important in assessing the solubility increase achieved and the stability thereof, enabling the rational development of these systems.

\section{CONCLUSION}

Solid dispersion has emerged as one of the best technique to increase the solubility of the poorly water soluble drugs. Various hydrophilic polymers have been used for this purpose. Apart from these, the addition of surfactants with propriety emulsifier has also been used. SD's are also prepared using cyclodextrins in multicomponent systems. One must be cautious in selected of hydrophilic polymer and the preparation technique. These preparation techniques also influence the properties of the solid dispersion as well as its ability to improve dissolution.

\section{CONFLICT OF INTEREST}

\section{The Author reports no conflict of interest}

\section{REFERENCES}

1. Khadka P, Ro J, Kim H, et al., Pharmaceutical particle technologies: an approach to improve drug solubility, dissolution and bioavailability, asian journal of pharmaceutical sciences, 2014, 9(6), 304-16.

2. Karavas E, Georgarakis E, Sigalas MP, Avgoustakis K, Bikiaris D, Investigation of the release mechanism of a sparingly water-soluble drug from solid dispersions in hydrophilic carriers based on physical state of drug, particle size distribution and drug-polymer interactions, European journal of pharmaceutics and biopharmaceutics, 2007, 66(3), 334-47.

3. Karanth H, Shenoy VS, Murthy RR, Industrially feasible alternative approaches in the manufacture of solid dispersions: A technical report, AAPS PharmSciTech, 2006, 7(4), E31-E8.

4. Patel RP, Patel DJ, Bhimani DB, Patel JK, Physicochemical characterization and dissolution study of solid dispersions of furosemide with polyethylene glycol 6000 and polyvinylpyrrolidone K30, Dissolution Technol, 2008, 15(3), 17-25.

5. Loftsson T, Hreinsdóttir D, Másson M, Evaluation of cyclodextrin solubilization of drugs, International journal of pharmaceutics, 2005, 302(1), 18-28.

6. Singh J, Walia M, Harikumar S, Solubility enhancement by solid dispersion method: a review, Journal of Drug Delivery and Therapeutics, 2013, 3(5), 148-55.

7. Bikiaris D, Papageorgiou GZ, Stergiou A, et al., Physicochemical studies on solid dispersions of poorly water-soluble drugs: evaluation of capabilities and limitations of thermal analysis techniques, Thermochimica acta, 2005, 439(1), 58-67.

8. Serajuddin A, Solid dispersion of poorly water-soluble drugs: Early promises, subsequent problems, and recent breakthroughs, Journal of pharmaceutical sciences, 1999, 88(10), 1058-66.

9. Leonardi D, Barrera MG, Lamas MC, Salomón CJ, Development of prednisone: polyethylene glycol 6000 fastrelease tablets from solid dispersions: solid-state characterization, dissolution behavior, and formulation parameters, AAPS PharmSciTech, 2007, 8(4), 221-8.

10. Allawadi D, Singh N, Singh S, Arora S, Solid dispersions: a review on drug delivery system and solubility enhancement, 
International Journal of Pharmaceutical Sciences and Research, 2013, 4(6), 2094.

11. Janssens S, de Armas HN, D'Autry W, Van Schepdael A, Van den Mooter G, Characterization of ternary solid dispersions of Itraconazole in polyethylene glycol 6000/polyvidone-vinylacetate 64 blends, European journal of pharmaceutics and biopharmaceutics, 2008, 69(3), 111420.

12. Sareen S, Mathew G, Joseph L, Improvement in solubility of poor water-soluble drugs by solid dispersion, International journal of pharmaceutical investigation, 2012, 2(1), 12.

13. Sethia S, Squillante III E, Solid dispersions: revival with greater possibilities and applications in oral drug delivery, Critical Reviews ${ }^{\mathrm{TM}}$ in Therapeutic Drug Carrier Systems, 2003, 20(2\&3).

14. Vasconcelos T, Sarmento B, Costa P, Solid dispersions as strategy to improve oral bioavailability of poor water soluble drugs, Drug discovery today, 2007, 12(23), 1068-75.

15. Vilhelmsen $\mathrm{T}$, Eliasen $\mathrm{H}$, Schæfer $\mathrm{T}$, Effect of a melt agglomeration process on agglomerates containing solid dispersions, International journal of pharmaceutics, 2005 , 303(1), 132-42.

16. Cirri M, Mura P, Rabasco A, Gines J, Moyano J, Gònzalez-Rodrìguez $\mathrm{M}$, Characterization of ibuproxam binary and ternary dispersions with hydrophilic carriers, Drug development and industrial pharmacy, 2004, 30(1), 65-74.

17. Yang G, Zhao Y, Feng N, Zhang Y, Liu Y, Dang B, Improved dissolution and bioavailability of silymarin delivered by a solid dispersion prepared using supercritical fluids, asian journal of pharmaceutical sciences, 2015, 10(3), 194-202.

18. Chaturvedi A, Verma A, Solubility enhancement of poorly water soluble drugs by solid dispersion, International Journal of Pharmaceutical Sciences and Research, 2012, 3(1), 26.

19. Karataş A, Yüksel N, Baykara T, Improved solubility and dissolution rate of piroxicam using gelucire 44/14 and labrasol, Il Farmaco, 2005, 60(9), 777-82.

20. Ohara T, Kitamura S, Kitagawa T, Terada K, Dissolution mechanism of poorly water-soluble drug from extended release solid dispersion system with ethylcellulose and hydroxypropylmethylcellulose, International journal of pharmaceutics, 2005, 302(1), 95-102.

21. Liu L, Wang X, Improved dissolution of oleanolic acid with ternary solid dispersions, AAPS PharmSciTech, 2007, 8(4), 267-71.

22. Janssens S, Denivelle S, Rombaut P, Van den Mooter G, Influence of polyethylene glycol chain length on compatibility and release characteristics of ternary solid dispersions of itraconazole in polyethylene glycol/hydroxypropylmethylcellulose 2910 E5 blends, European journal of pharmaceutical sciences, 2008, 35(3), 203-10.

23. Loh ZH, Samanta AK, Heng PWS, Overview of milling techniques for improving the solubility of poorly watersoluble drugs, asian journal of pharmaceutical sciences, 2015, 10(4), 255-74.

24. Singh M, Hemant K, Ram M, Shivakumar H, Microencapsulation: a promising technique for controlled drug delivery, Research in pharmaceutical sciences, 2011, 5(2), 65-77.

25. Chauhan B, Shimpi S, Paradkar A, Preparation and evaluation of glibenclamide-polyglycolized glycerides solid dispersions with silicon dioxide by spray drying technique, European journal of pharmaceutical sciences, 2005, 26(2), 219-30.

26. Zajc N, Obreza A, Bele M, Srčič S, Physical properties and dissolution behaviour of nifedipine/mannitol solid dispersions prepared by hot melt method, International journal of pharmaceutics, 2005, 291(1), 51-8.

27. Mehta S, Joseph NM, Feleke F, Palani S, IMPROVING SOLUBILITY OF BCS CLASS II DRUGS USING SOLID
DISPERSION: A REVIEW, Journal of Drug Delivery and Therapeutics, 2014, 4(3), 7-13.

28. Hasegawa S, Hamaura T, Furuyama N, Kusai A, Yonemochi E, Terada K, Effects of water content in physical mixture and heating temperature on crystallinity of troglitazone-PVP K30 solid dispersions prepared by closed melting method, International journal of pharmaceutics, 2005, 302(1), 10312.

29. Juppo AM, Boissier C, Khoo C, Evaluation of solid dispersion particles prepared with SEDS, International journal of pharmaceutics, 2003, 250(2), 385-401.

30. Fernandez M, Rodriguez IC, Margarit MV, Cerezo A, Characterization of solid dispersions of piroxicam/polyethylene glycol 4000, International journal of pharmaceutics, 1992, 84(2), 197-202.

31. Modi A, Tayade P, Enhancement of dissolution profile by solid dispersion (kneading) technique, AAPS PharmSciTech, 2006, 7(3), E87-E92.

32. Corrigan DO, Healy AM, Corrigan OI, The effect of spray drying solutions of polyethylene glycol (PEG) and lactose/PEG on their physicochemical properties, International journal of pharmaceutics, 2002, 235(1), 193205.

33. Savjani KT, Gajjar AK, Savjani JK, Drug solubility: importance and enhancement techniques, ISRN pharmaceutics, 2012, 2012.

34. Khan AD, Singh L, VARIOUS TECHNIQUES OF BIOAVAILIBILITY ENHANCEMENT: A REVIEW, Journal of Drug Delivery and Therapeutics, 2016, 6(3), 3441.

35. Chaudhari SP, Dave RH, To prepare and characterize microcrystalline cellulose granules using water and isopropyl alcohol as granulating agents and determine its end-point by thermal and rheological tools, Drug development and industrial pharmacy, 2015, 41(5), 744-52.

36. Al-Marzouqi AH, Jobe B, Dowaidar A, Maestrelli F, Mura P, Evaluation of supercritical fluid technology as preparative technique of benzocaine-cyclodextrin complexesComparison with conventional methods, Journal of pharmaceutical and biomedical analysis, 2007, 43(2), 56674.

37. Broman E, Khoo C, Taylor LS, A comparison of alternative polymer excipients and processing methods for making solid dispersions of a poorly water soluble drug, International journal of pharmaceutics, 2001, 222(1), 139-51.

38. Loftsson T, Masson M, Brewster ME, Self-association of cyclodextrins and cyclodextrin complexes, Journal of pharmaceutical sciences, 2004, 93(5), 1091-9.

39. Vasanthavada M, Tong W-QT, Joshi Y, Kislalioglu MS, Phase behavior of amorphous molecular dispersions II: Role of hydrogen bonding in solid solubility and phase separation kinetics, Pharmaceutical research, 2005, 22(3), 440-8.

40. Valero M, Pérez-Revuelta BI, Rodríguez LJ, Effect of PVP $\mathrm{K}-25$ on the formation of the naproxen: $\beta$-ciclodextrin complex, International journal of pharmaceutics, 2003, 253(1), 97-110.

41. Katti VS, Kadam AM, Honmane SM, Patil S, Patil S, Bhamare K, IMPROVEMENT OF SOLUBILITY AND DISSOLUTION RATE OF CANDESARTAN CILEXETIL BY SOLID DISPERSION IN POLYVINYL PYRROLIDONE, International Journal of Pharmaceutical Sciences and Research, 2014, 5(4), 1550.

42. Chaudhari SP, Dave RH, Investigating the Effect Of Molecular Weight of Polyvinylpyrrolidone and Hydroxypropyl Methyl Cellulose as Potential Antiprecipitants on Supersaturated Drug Solutions and Formulations using Weakly Acidic Drug: Indomethacin, International Journal of Pharmaceutical Sciences and Research, 2016, 7(10), 3931-48.

43. Chaudhari SP, Dave RH, Evaluating the Effects of Different Molecular Weights of Polymers in Stabilizing Supersaturated Drug Solutions and Formulations Using Various Methodologies of the Model Drug: Fenofibrate, Journal of 
Pharmaceutical Sciences and Pharmacology, 2015, 2(3), 259-76.

44. Kadajji VG, Betageri GV, Water soluble polymers for pharmaceutical applications, Polymers, 2011, 3(4), 19722009.

45. Patil MP, Gaikwad NJ, Preparation and characterization of gliclazide-polyethylene glycol 4000 solid dispersions, Acta pharmaceutica, 2009, 59(1), 57-65.

46. Marsac PJ, Li T, Taylor LS, Estimation of drug-polymer miscibility and solubility in amorphous solid dispersions using experimentally determined interaction parameters, Pharmaceutical research, 2009, 26(1), 139-51.

47. Leuner C, Dressman J, Improving drug solubility for oral delivery using solid dispersions, European journal of pharmaceutics and biopharmaceutics, 2000, 50(1), 47-60.

48. Wang W, Yang X, Fang Y, Ding J, Yan J, Preparation and thermal properties of polyethylene glycol/expanded graphite blends for energy storage, Applied Energy, 2009, 86(9), 1479-83.

49. DHILLON V, TYAGI R, Solid dispersion: a fruitful approach for improving the solubility and dissolution rate of poorly soluble drugs, Journal of Drug Delivery and Therapeutics, 2012, 2(4).

50. Kapsi SG, Ayres JW, Processing factors in development of solid solution formulation of itraconazole for enhancement of drug dissolution and bioavailability, International journal of pharmaceutics, 2001, 229(1), 193-203.

51. Kushida I, Ichikawa M, Asakawa N, Improvement of dissolution and oral absorption of ER-34122, a poorly water-soluble dual 5-lipoxygenase/cyclooxygenase inhibitor with anti-inflammatory activity by preparing solid dispersion, Journal of pharmaceutical sciences, 2002, 91(1), 258-66.

52. Yamashita K, Nakate T, Okimoto K, et al., Establishment of new preparation method for solid dispersion formulation of tacrolimus, International journal of pharmaceutics, 2003, 267(1), 79-91.

53. Siepmann J, Peppas N, Modeling of drug release from delivery systems based on hydroxypropyl methylcellulose (HPMC), Advanced drug delivery reviews, 2001, 48(2), 13957.

54. Khoo S-M, Porter CJ, Charman WN, The formulation of halofantrine as either non-solubilising PEG 6000 or solubilising lipid based solid dispersions: physical stability and absolute bioavailability assessment, International journal of pharmaceutics, 2000, 205(1), 65-78.

55. Koga K, Kusawake Y, Ito Y, Sugioka N, Shibata N, Takada $\mathrm{K}$, Enhancing mechanism of Labrasol on intestinal membrane permeability of the hydrophilic drug gentamicin sulfate, European journal of pharmaceutics and biopharmaceutics, 2006, 64(1), 82-91.

56. Shah TJ, Amin AF, Parikh JR, Parikh RH, Process optimization and characterization of poloxamer solid dispersions of a poorly water-soluble drug, AAPS PharmSciTech, 2007, 8(2), E18-E24.

57. Berg JM, Tymoczko JL, Stryer L, Chemical bonds in biochemistry, 2002.

58. Asbahr ACC, Franco L, Barison A, Silva CW, Ferraz HG, Rodrigues LN, Binary and ternary inclusion complexes of finasteride in HP $\beta C D$ and polymers: Preparation and characterization, Bioorganic \& medicinal chemistry, 2009, 17(7), 2718-23.

59. Ribeiro LS, Ferreira DC, Veiga FJ, Physicochemical investigation of the effects of water-soluble polymers on vinpocetine complexation with $\beta$-cyclodextrin and its sulfobutyl ether derivative in solution and solid state, European journal of pharmaceutical sciences, 2003, 20(3), 253-66.

60. Ribeiro L, Carvalho RA, Ferreira DC, Veiga FJ, Multicomponent complex formation between vinpocetine, cyclodextrins, tartaric acid and water-soluble polymers monitored by NMR and solubility studies, European journal of pharmaceutical sciences, 2005, 24(1), 1-13.

61. Singh R, Jain A, DEVELOPMENT, CHARACTERIZATION \& STABILIZATION OF POORLY WATER SOLUBLE DRUGS UTILIZING SOLID DISPERSION TECHNIQUES BY USING BCYCLODEXTRIN, Journal of Drug Delivery and Therapeutics, 2013, 3(1).

62. Wulff M, Aldén M, Phase equilibria in drug-polymersurfactant systems, Thermochimica acta, 1995, 256(1), 15165.

63. Bibby DC, Davies NM, Tucker IG, Mechanisms by which cyclodextrins modify drug release from polymeric drug delivery systems, International journal of pharmaceutics, 2000, 197(1), 1-11. 